I.M.C. Clarke MB ChB FRCA, J.E. Morin BA I. Warnell MB BS FRCA*

\title{
Personality factors and the practice of anaesthesia: a psycho- metric evaluation
}

The purpose of this study was to examine personality profiles of Canadian anaesthetists and to investigate the role of personality variables in anaesthetist's job satisfaction. Three hundred and thirty senior Canadian anaesthetists completed the Cattell $16 P F$ personality inventory. A brief demographic questionnaire enquired about special interests and job satisfaction. This paper reports the initial analysis of the replies. Most anaesthetists were very satisfied with their work. Female anaesthetists are more tender-minded, sensitive and over-protective than their male colleagues.

Cette étude vise à déterminer les profils de personnalité des anesthésistes canadiens et le rôle que jouent les variables de la personnalité au regard de la satisfaction professionnelle. Trois cent trente-trois anesthésistes séniors canadiens ont complété l'inventaire de personnalité de Cattell 16 PF. Un court questionnaire démographique portait sur les intérêts spéciaux et la satisfaction professionnelle. Cet article rapporte l'analyse initiale des réponses. La plupart des anesthésistes sont très satisfaits de leur profession. Les femmes anesthésistes sont plus aisément émotives, sensibles et surprotectrices que les hommes.

The use of questionnaires to examine personality has been an important part of personnel selection for many years. Both military and civilian organizations commonly

\section{Key words}

ANAESTHETISTS: personality;

MANPOWER: anaesthetists.

From the Department of Anaesthesia, Foothills Hospital and the University of Calgary, 1403 - 29 Street N.W., Calgary, Alberta, T2N 2T9. *Present address: Department of Anaesthetics, Newcastle General Hospital, Newcastle-uponTyne, England.

Address correspondence to: Dr. I.M.C. Clarke, Department of Anaesthesia, Foothills Hospital and the University of Calgary, 1403 - 29 Street N.W., Calgary, Alberta, Canada T2N $2 \mathrm{~T} 9$.

Accepted for publication 20th January, 1994. employ such methods in addition to conventional interview and other techniques to determine aptitude, usually in the context of middle to senior management positions.

Medicine continues to select its senior physicians on the basis of reputation and paper qualifications without formal testing of individual characteristics which could seriously affect their ability to function under stress or in situations which deviate from the expected. In 1969, Walton and Last' indicated that "personality differences among young doctors are of relevance to ... career advice, vocational counseling and ... appointment committees." A few recent attempts have been made to improve the selection of medical students ${ }^{2,3}$ and trainees ${ }^{4-10}$ but most physicians seem satisfied with the status quo. Yet morbidity and mortality figures for physicians are poor compared with equal rank executives in the commercial or military world: problems include drug and alcohol abuse, marital breakdown, personal illness and suicide.?

The Cattell 16PF personality questionnaire ${ }^{12}$ has been the most widely employed and best validated of its type and, with modifications, has been used throughout the English-speaking business world for $30 \mathrm{yr}$. The inventory can be administered individually, to a group, or can be used as a self-report test (as in this study). There are 105 questions which are scored using a series of templates which separate the questions into groups scoring 16 different personality characteristics. Standard scores are a measure of relative standing in a group arrived at by transforming raw scores from different distributions. For example, the most common standard score is the " $z$ score." We have used sten scores as presented in Cattell's handbook for the 16PF inventory. A ten-point scale range is used, each unit being called a sten (the derivation is the same as that of stanines from a nine-point scale). This method of scoring allows statistical comparisons to be made between different groups tested in different places at different times.

There appears to have been no use made of such personality questionnaires in the selection of senior physicians although the Department of Anaesthetics in Candiff has used the Cattell 16PF to assess aspiring trainees ${ }^{3}$ 
and prospective studies are now in progress with medical students. "

The present study used a randomized sample of anaesthetists drawn from two anglophone Canadian provinces. Since Cattell indicated that this questionnaire "can be virtually self-administering" 12 it was felt to be acceptable to employ a postal self-report process. The validity of this approach has been confirmed by the distributors of the questionnaire. ${ }^{13}$

It was hoped to study a large group of anaesthetists who had already decided on their subspecialty (if any). Thus the study sample was taken from physicians holding staff posts (i.e., no residents or other trainees) and the study list was prepared from the 1988 membership of the Canadian Anaesthetists' Society (CAS). It was assumed that those who were members of the Society might have more interest in their professional activities than those who were not members of a professional specialty organization.

\section{Methods}

The study group was taken from staff anaesthetists in both Alberta and Ontario using a random number series, half the anaesthetits as described above practicing in Ontario and Alberta were abstracted from the CAS membership list and circulated with a questionnaire package. This included the Cattell 16PF Form " $\mathrm{C}$ " and also a brief demographic questionnaire (Appendix I). The institutional Research Ethics Committee indicated that their consent was not required since no patients or patient data were involved and participation by any physician was entirely voluntary and confidential.

On receipt of the completed questionnaires the Cattell was separated from the demographic questionnaire by a secretary not involved in any part of the study and the Cattell 16PF was then scored by one of the investigators (IW) using the technique described by Cattell in the handbook for the questionnaire. The demographic questionnaire was then entered on computer and only in the final stages were the two parts of the study brought together. Neither investigator was aware of the identity of the respondents although a master list kept by a third party allowed names and numbers to be matched. The purpose of this was to allow those respondents who wished to know their Cattell profile to receive this information so they could compare their own personality profile with that of the general population (many took advantage of this feature).

The Cattell 16PF results were analyzed using the Statistical Package for the Social Sciences (SPSS). ${ }^{14}$

\section{Results}

Of 780 physicians who were sent the original two-part
TABLE I Basic demographic data

\begin{tabular}{ll}
\hline Questionnaires mailed & 780 \\
Replies & 348 \\
Useable replies & $330,42.3 \%$ \\
Male & $265,79.4 \%$ \\
Female & $63,18.6 \%$ \\
Not stated & 2 \\
Mean age & 44.4 \\
SD & 14.75 \\
& \\
Geographical distribution & \\
Alberta & 110 \\
Ontario & 220 \\
& \\
Marital status & \\
Married & $87 \%$ \\
Single & $8.2 \%$ \\
Divorced & $3 \%$ \\
Not known & $1.8 \%$ \\
Country of qualification & \\
Canada & \\
United Kingdom & $222,67.2 \%$ \\
Rest of the world & $61,18.5 \%$ \\
& $47,14.3 \%$ \\
Job satisfaction VAS & \\
Mean & 60.82 \\
SD & 22.67 \\
\hline
\end{tabular}

questionnaire in 1988, $330(42.31 \%)$ returned usable replies. A number of physicians wrote accompanying letters amplifying their responses to the demographic questionnaire and some who declined to complete the questionnaire still wrote explaining why. Twenty-three papers were spoiled because physicians did not understand the concept of Visual Analogue Scale (VAS) or returned interesting but unusable questionnaires where they had ignored the questions and just written comments (some of which were extremely derogatory of medicine in general and anaesthesia in particular). Two physicians indicated that the questionnaire provoked enough selfexamination for them to resign their posts.

All respondents were staff anaesthetists, some ("specialists") having a major sub-specialty interest such as cardiothoracic or paediatric anaesthesia.

The main findings of the demographic questionnaire are summarised in Table I. The age distribution of the sample is shown in Figure 1.

Job satisfaction expressed on a visual analogue scale indicated that the majority of anaesthetists were very happy with their work (mean VAS scores for specialist anaesthetists $63.9 \pm 20.8$ and for non-specialists $57.9 \pm$ 23.9) and did not contemplate any change, whether to another specialty or out of medicine together. Within the 


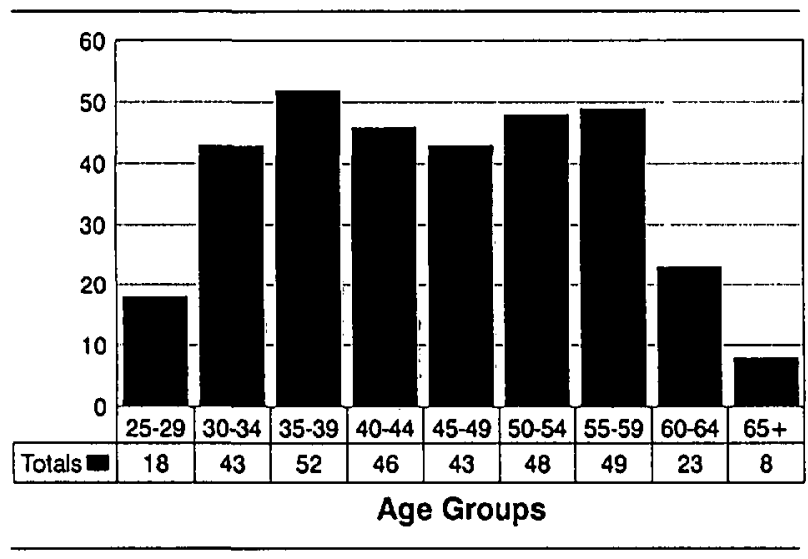

FIGURE 1 Distribution of age groups $(n=330)$.

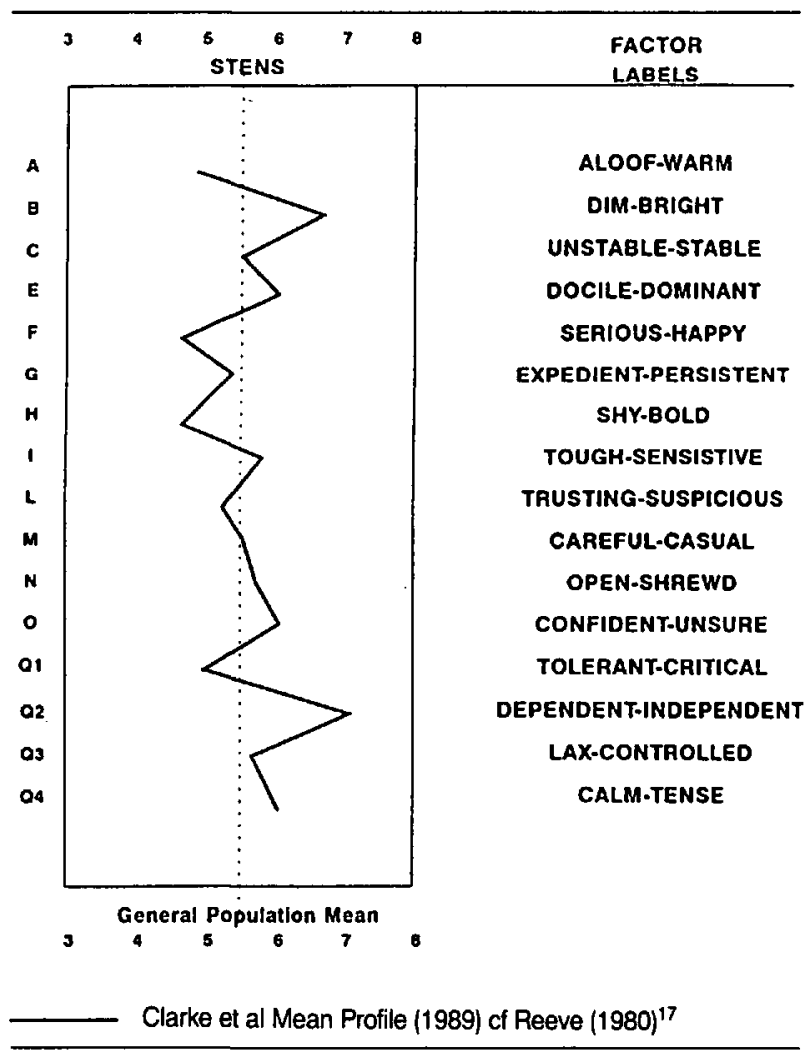

FIGURE 2 Anaesthetists-16PF form C-mean profile $(n=330)$.

specialist anaesthetist group the least satisfied (VAS score at least 1 standard deviation below mean $n=37 / 259$ ) were seven years younger on average than the satisfied group (VAS at least 1 standard deviation above mean $n=25 / 259)$ and to be UK qualified practicing in Ontario $(P<0.004)$.

The Ontario doctors were a much less homogeneous group than those in Alberta and included not just the least satisfied but also the most satisfied (two doctors
TABLE II Summary of Cattell's 16 personality factors mean stem scores

\begin{tabular}{ll}
\hline Factors & Mean \\
\hline (A) Aloof-warm & 4.38 \\
(B) Dim-bright & 6.74 \\
(C) Unstable-stable & 6.01 \\
(E) Docile-Dominant & 5.77 \\
(F) Serious-happy & 4.38 \\
(G) Expedient-conscientious & 6.49 \\
(H) Shy-bold & 4.94 \\
(I) Tough-sensitive & 5.27 \\
(L) Trusting-suspicious & 4.81 \\
(M) Careful-casual & 5.39 \\
(N) Open-shrewd & 5.63 \\
(O) Confident-unsure & 5.17 \\
(Q1) Tolerant-critical & 5.62 \\
(Q2) Dependent-independent & 7.02 \\
(Q3) Lax-controlled & 6.37 \\
(Q4) Calm-tense & 5.24 \\
\hline
\end{tabular}

TABLE III Correlation table of personality factors with age and years of service

\begin{tabular}{lcc}
\hline Factors & Age & Years of service \\
\hline (A) Aloof-warm & 0.0548 & -0.0346 \\
(B) Dim-bright & -0.0933 & $-0.1737^{*}$ \\
(C) Unstable-stable & $0.1554^{*}$ & 0.0885 \\
(E) Docile-dominant & -0.0610 & -0.0958 \\
(F) Serious-happy & -0.0857 & -0.1076 \\
(G) Expedient-conscientious & $0.1587^{*}$ & $0.2243 \dagger$ \\
(H) Shy-bold & 0.0129 & -0.0599 \\
(I) Tough-sensitive & 0.0396 & 0.0229 \\
(L) Trusting-suspicious & -0.0034 & 0.0152 \\
(M) Careful-casual & 0.0104 & -0.0206 \\
(N) Open-shrewd & -0.0048 & 0.0884 \\
(O) Confident-unsure & -0.1212 & -0.1004 \\
(Q1) Tolerant-critical & 0.0272 & -0.0981 \\
(Q2) Dependent-independent & -0.1109 & -0.0347 \\
(Q3) Lax-controlled & 0.1359 & 0.1073 \\
(Q4) Calm-tense & -0.0885 & -0.0737 \\
\hline
\end{tabular}

${ }^{*} P<0.01 . \dagger P<0.001$

qualified in the Far East whose VAS scores for satisfaction were well right of the maximum terminator and accompanied by written comments). The results of the Cattell 16PF inventory are summarised in Table II and Figure 2.

There were positive correlations using Pearson's coefficient $(P<0.01)$ with age and years of practice in several personality components as defined by Cattell's $16 \mathrm{PF}$ inventory (Table III).

They include a higher mean in factors $\mathrm{C}$ (emotional stability), $\mathrm{G}$ (conscientiousness), and Q3 (self-sentiment integration) with an increase in age. Factor $G$ mean is correlated $(P<0.01)$ with years of service. Factor B (insightfulness, fast learning and adaptability) mean 
scores decrease significantly with an increase in years of service $(P<0.01)$

Noteworthy positive associations with factor I (tender mindfulness, sensitivity and overprotection traits) $(P<$ 0.001 ) and Factor $O$ (insecurity, self-reproaching and apprehensive traits) occurred in this sample of female anaesthetists $(P<0.001)$. Also, female anaesthetists had fewer years of total service $(\mathrm{x}=11.79)$ than male anaesthetists $(\mathrm{x}=18.07)(P<0.01)$.

In the marital status groups, married anesthetists had a higher $(\mathrm{x}=5.96, P<0.01)$ mean score in Factor $\mathrm{M}$, less practicality and more imaginative traits, and lower mean scores $(\mathrm{x}=5.15, P<0.01)$ in Factor $\mathrm{N}$, forthright and unpretentious traits.

The work satisfaction scale revealed a positive correlation with Factor $C$, emotional stability $(P<0.001)$, and a negative correlation with years of service $(P<$ 0.001 ). The work satisfaction scale was also negatively correlated to the mean score of Factor L; suspecting, jealous and pretension traits $(P<0.01)$.

\section{Discussion}

The anaesthetists in this study group were intelligent, somewhat dominant yet sensitive, independent yet somewhat unsure and rather tense. They were also tolerant, shy and rather serious.

One result was surprising; women physicians were more tender-minded, sensitive and overprotective than their male counterparts, yet the majority of personality studies in the general population show no sex differences except for aggression. ${ }^{15}$ Women anaesthetists have fewer years in their specialty (presumably because of child rearing).

Emotional stability and self-esteem both increase with age but this does not lead to complacency since conscientiousness is also more often seen in the older anaesthetists who has more years in the specialty. This is perhaps just as well since the older anaesthetist shows a significant decline in insight as well as less ability to learn or adapt rapidly to new situations.

Female anaesthetists were less confident, more insecure and apprehensive than male colleagues and were much more likely to feel guilty than the men. This seems surprising in view of the rapidly increasing numbers of women in medicine, and anaesthesia in particular, unless it reflects the continuing male dominance of administration and teaching which perpetuates the sexist attitudes of the past.

Married anaesthetists of either sex were significantly less practical and forthright than unmarried physicians; perhaps wedlock functions to lower the individual's confidence and contact with reality or maybe one simply learns more about peaceful coexistence. Conversely, mar- ried anaesthetists were more imaginative than the unmarried and yet more pretentious; maybe the facade this produces can compensate for domestic disharmony by facilitating daydreaming.

Most anaesthetists appeared fairly satisfied with their working conditions and some indicated that work was the most important aspect of their lives. A few were extremely unhappy and two commented that they had resigned their jobs in disgust at the time they completed the questionnaire, both leaving medicine completely.

Although the experienced anaesthetists were more selfconfident and conscientious than younger doctors they were less happy in their work. Poor job satisfaction is also linked to being suspicious, jealous and pretentious, i.e., not surprisingly, the doctor who has unrealistic expectations becomes a little paranoid when his hopes are not fulfilled and does not enjoy his work. The most satisfied physicians were those who were the most emotionally stable and, by implication, have a more realistic expectation of life.

This is the largest sample of specialist anaesthetists examined by personality. They came from diverse backgrounds yet demonstrated many similarities. They were, on the whole, remarkably happy in their work (in spite of impressions that this is not the case) and those who expressed significant disquiet formed a distinct group. The female anaesthetists were different both in demographics and personality from the male anaesthetists.

Howat in the 1977 Frederick Hewitt lecture, ${ }^{16}$ described the "typical" anaesthetist as "wishes to be a member of a team ... is by nature gregarious ... 'a clubbable man' (with) a keen sense of humour," "change appeals to him." A classic study by Reeve ${ }^{17}$ and ours indicate these assumptions are seriously flawed and, since $78.3 \%$ of the 317 anaesthetists Howat polled found anaesthesia as a career "unsatisfactory," emphasizes the potential importance of objective personality testing in medical career guidance and selection.

Whilst preserving anonymity, personality variables can be correlated with a number of demographic details and norms established which could be used for future studies in Canada. It would have been interesting to include Francophone regions in the study too but it was felt that this would complicate an already difficult task. In addition the comparative work from the past has all been in English-speaking populations.

\section{Acknowledgements}

The authors would like to thank the Canadian Anaesthetists' Society who supplied the membership lists for Alberta and Ontario without cost. Much informal help was given by a psychiatric colleague, Dr. D. Barnes. 


\section{Appendix I}

\section{Demographic Questionnaire}

\section{Demographic and Practise Data}

Please answer the following questions by marking in the appropriate box or by writing in the space provided

Please indicate if you practise a subspeciality;

$\square$ Pediatric anaesthesia and intensive care

$\square$ Cardiothoracic

$\square$ Neuroanaesthesia

$\square \mathrm{ICU}$

$\square$ Obstetric anaesthesia and analgesia

$\square$ Chronic pain

$\square$ Other (please specify)

If you do not spend all your working sessions in clinical anaesthesia, how do you spend the rest of your working week?

$\square$ Research

$\square$ Teaching

$\square$ Administration

$\square$ Fishing/golf etc.

Please indicate on this linear analogue scale approximately where you would rate your present job satisfaction:

Resigning tomorrow Fantastic: only reason for living

Which if any of the following influenced your choice of clinical activity:

$\square$ Money

$\square$ High status

$\square$ Fast promotion

$\square$ Family members in medicine

$\square$ Research opportunities

$\square$ Choice of place to live

$\square$ Less patient contact

$\square$ Chance

$\square$ None of the above

Would you change medical specialty if you had the opportunity?

$\square$ Yes

$\square$ No

If yes, to what would you change?

Would you have preferred a different career to medicine?

$\square$ Yes

$\square$ No

If yes what would you have preferred to do?

Please complete the following demographic data

Age.. Sex Male $\square$ Female $\square$ Marital Status...........

Year of qualification........ Province/Country of qualification............

Other medical/non-medical qualifications.

Years spent in anaesthesia.

Thank you for your help. We hope you find the rest of this questionnaire interesting.

\section{References}

1 Walton HJ, Last JM. Young doctors aiming to enter different specialties. BMJ 1969; 2; 752-4.

2 Vickers $M D$, Reeve PE. Selection methods in medicine: a case for replacement surgery? (Editorial) J R Soc Med 1990; 83: 541-2.

3 Green A, Peters TJ, Webster DJT. Preclinical progress in relation to personality and academic profiles. Med Educ 1993; 27: 137-42.

4 Gough HG, Bradley P, McDonald JS Performance of residents in anaesthesiology as related to measures of personality and interests. Psychol Rep 1991; 68: 979-94.

5 Bruce DL, Katz SE, Turndorf H, Trounstine P, Hardesty $A$. Psychometric comparisons of trainees and consultants in anaesthesia and psychiatry. Br J Anaesth 1983; 55: 1259-64.

6 Gough $M H$, Holdsworth R, Bell JA, et al. Personality assessment techniques and aptitude testing as aids to the selection of surgical trainees. Ann R Coll Surg Engl 1988; 70: 265-79.

7 Cooper CL, Rout U, Faragher B. Mental health, job satisfaction and job stress among general practitioners. BMJ 1989; 298: 366-70.

8 Altmaier EM, Johnson SR, Tarico VS, Laube D. An empirical specification of residency performance dimensions. Obstet Gynecol 1988; 72: 126-30.

9 King $J$, Whitfield $M$. How to choose a new partner in general practice. BMJ 1990; 301: 1258-60.

10 Kramer $M$, Schmalenberg $C$. Job satisfaction and retention. Insights for the 90's. Nursing 1991; 21: 50-5.

11 Davies JM. Personal communication, 1990.

12 Cattell RB, Eber HW, Tatsuoka MM. Handbook for the sixteen personality factor questionnaire (16 PF). Institute for Personality and Ability Testing Inc.; Champaign, Ill., 1970.

13 Siers $M$. Institute for Personality and Ability Testing Inc.; Champaign, Ill. Personal Communication, 1993.

14 Norušis MJ. Statistical Package for the Social Sciences, (SPSS/PC+), SPSS Inc., Chicago, 1990.

15 Kalat JW. Introduction to Psychology. Belmont, CA: Wadsworth Publishing Company, 1985; 338.

16 Howat DDC. Anaesthesia as a career. Anaesthesia 1977; 32; 979-93.

17 Reeve PE. Personality characteristics of a sample of anaesthetists. Anaesthesia 1980; 35: 559-68. 